J. Natn. Sci. Coun. Sri Lanka 199422 (Suppl. A):S33-S35

\title{
BIOTECHNOLOGY AT KEELLS AGRO PRODUCTS LIMITED
}

\author{
Y. ILANGAKOON \\ Keells Agro Products Ltd, P.O. Box 10, Temple Road, Ekala, Ja-ela
}

Keells Agro Products Limited was incorporated to industrially cultivate and export "Shii Take" mushroom. The Japanese term Shii Take means oak mushrooms, Shii being the word for oak and Take being the word for mushroom. It is so called because the mushroom traditionally grows on dead oak trees. This mushroom is indigenous to countries such as Indonesia, China, Taiwan, Korea and Japan.

In these countries, the mushroom is grown in a traditional method which has a life cycle of six years. For this reason, the mushroom is considered rare and is highly priced. At Keells, the six year cycle has been telescoped to six months by the use of a special biotechnology which is patented world wide. A flow chart of the procedures involved in the traditional method is compared below with that of the biotechnology used at Keells.

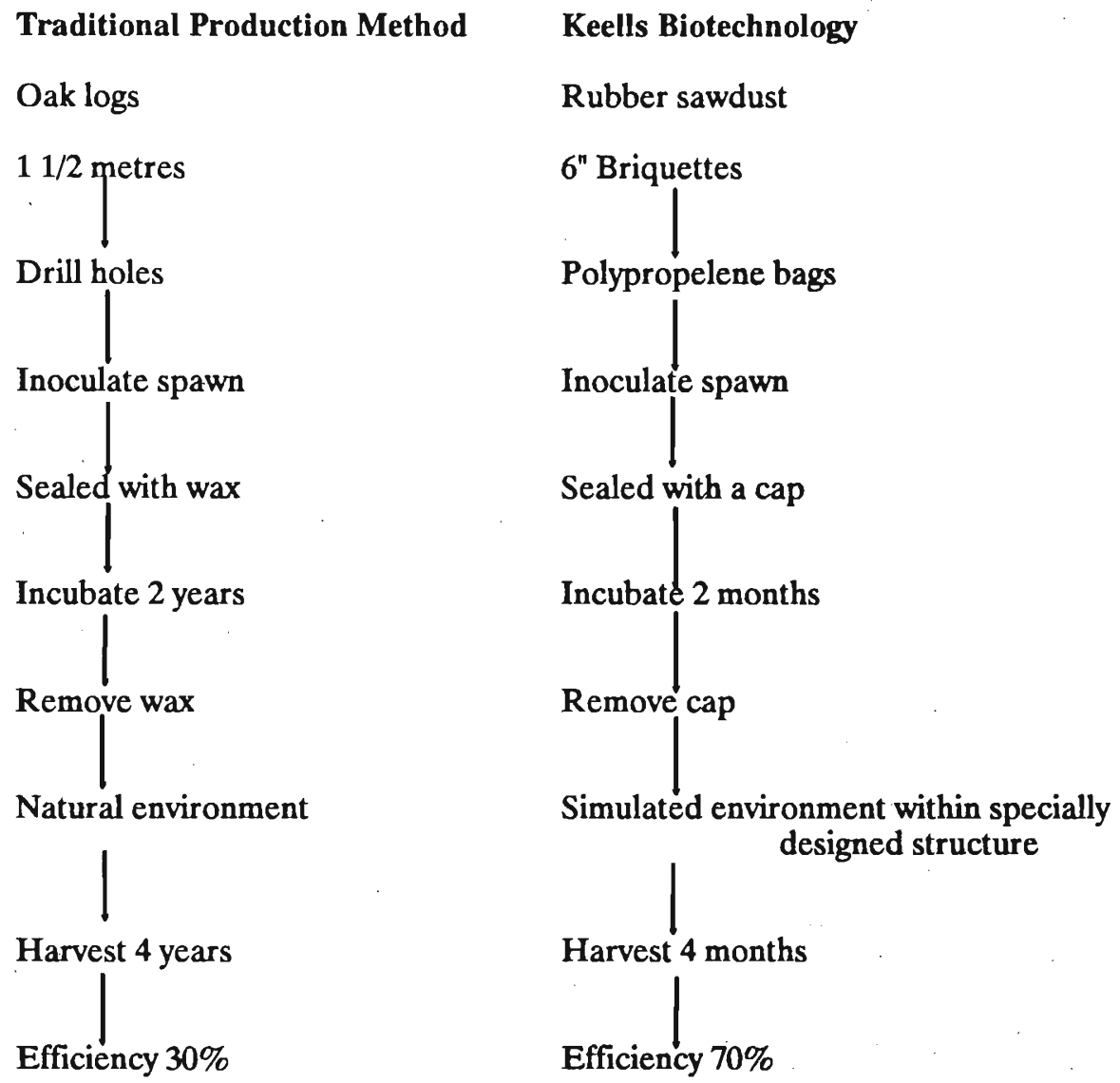




\section{Research and Development Requirements}

In order to maintain the competitive advantage the Company has acquired by using this biotechnology for the first time in the world, it is necessary to conduct continuous research and development on the technology. Due to the limited resources available in Sri Lanka, this has been done on a very low key at the project. If this is continued, our.present status as the world's largest single producer of this type of mushrooms and market leader in some European countries would soon diminish. Therefore it is essential that we utilize the available resources within Sri Lanka to conduct our research by sub contracting, and thereby supplement our in house development activities.

The research and development requirements of the Company are both within and outside the sphere of biotechnology. Therefore all these needs are explained below in the expectation that those within as well as those outside the biotechnology field would be aware of our requirements and assist us in our research and development efforts.

\section{Enrichment of Substrate}

The mushrooms grow utilizing nutrients such as cellulose available in the sawdust as well as organic additions to the substrate such as rice bran and rice germ. It is necessary to conduct continuous research in this area to reduce cost of substrate and at the same time increase yield, by the use of various combinations of organic material.

\section{Development of Strains}

Electricity is one of the largest cost components of the project. Therefore it is necessary to develop strains which are capable of functioning at local ambient temperatures, thereby minimizing the necessity to air condition the mushroom growing houses. This will also allow Shii Take mushrooms to be grown by small farmers and thereby increase the volumes exported by the country.

Simultaneously it is necessary to develop high yielding strains in order to increase productivity.

\section{Medical/Clinical Research}

Shii Take mushrooms are supposed to have many desirable medicinal properties including the lowering of cholesterol, the cure of some types of cancer and tumors and the enhancing of the immune system. A brochure with 51 publications of these properties is now available. It may be prudent to conduct medical and clinical research on the medical properties of Shii Take mushrooms so that awareness could be created within the community. 


\section{Food Technology}

At present the Company exports $70 \%$ of its production in its fresh form and $30 \%$ in dehydrated form. The fresh mushrooms are air freighted and therefore attract a large cost component as air freight charges. Also the high perishability of fresh mushrooms requires the $1.5 \mathrm{MT}$ of mushrooms produced each day to be handled efficiently. Any break in the cold chain would reduce the shelf life. For this reason and for reasons of increasing net foreign exchange earnings by the country, it is necessary to add value through processing of the fresh mushrooms that are now being exported. Therefore, new processed products that can be sea freighted need to be developed.

\section{Post harvest technology}

The fresh mushrooms that are exported are transported to foreign destinations using direct airline flights from Sri Lanka. Whenever trans-shipments are used, to transport the goods to a destination where direct flights do not exist from Sri Lanka, the mushrooms arrive in poor condition. It is therefore necessary to conduct research into post harvest and packaging technology to develop treatment and packaging systems that could withstand trans-shipment and thereby allow the company to access new markets.

\section{Conclusion}

In conclusion, it is necessary to state that the universities need to play a more active role in meeting the research and development needs of industry in Sri Lanka. For the universities to do this, it is necessary for them to liaise more closely with industry and understand their needs so that they could thereafter cater to such needs. In order to do this, it may be prudent to incorporate into the curriculam of undergraduates as well as post graduates a period of industrial training consisting of $6-12$ months in their specialized fields of study. This would give the students an opportunity of understanding how the private sector works, as well as an opportunity for them to understand the needs of industry. Industry in turn will have the opportunity of working with under-graduate or post-graduate students specializing in various fields of activity and thereby have a resource bank to draw from for research needs, consultancy or recruitment.

Such industrial training should be in fields specified by industry. For example at Keells Agro Products Limited if we need to develop a new strain which is resistant to local ambient temperature, a university may place with the organization a student who is specializing in this field. Once the student's industrial training is over, ideally, the same supervisor should place another student with the organization to continue from the point that the previous student stopped. This would not only ensure continuity of research but also incremental research. 